\title{
LINGUISTICS AND SECOND LANGUAGE TEACHING: AN ASSESSMENT
}

\author{
Johann $L$ van der Walt \\ PU for CHE
}

\section{Introduction}

The relationship between linguistics and second language teaching has always been a controversial one. Many linguists have argued that linguistics has nothing to say to the teacher. Sampson (1980, p.10), for example, says: "I do not believe that linguistics has any contribution to make to the teaching of English or the standard European languages. The many people who claim that it has seem to me to deceive themselves and others". On the other hand, Johnson (1982,p.10) points out that language teachers have always looked to the linguist for guidance on how to teach languages. He says that language teachers have always considered linguistics as something of a mother discipline. Language after all, is what both the language teacher and the linguist are concerned with: the teacher is concerned with "teaching something which is the object of study of linguistics, and is described by linguistic methods" (Halliday, McIntosh and Strevens 1964, p.166). Linguistics will therefore always be a field of study relevant to language teaching. The problem, of course, is to determine the precise nature of this 'relevance'.

The aim of this paper is to assess the influence that linguistics has had on second language teaching. I shall give an overview of its influence, evaluate it, and then illustrate its present role in the search for a theory of second language acquisition. The question is whether linguistics can provide a comprehensive theory of second language acquisition; a theory which is an essential requirement in the teaching of second languages.

\section{Linguistics and second language teaching}

If one considers the relationship between linguistics and the teaching of English as a second language, it is obvious that linguistics has had an abiding influence which has moved through a number of phases. The relationship between linguistics and English Second Language teaching has shifted along a continuum from a direct relationship to a more indirect one. 
The best example of a direct relationship is the application of Structuralism to language teaching. The Structuralist approach to language was coupled with Behaviourist leaming principles, resulting in a scientific and confident application of linguistics to second language teaching in the audiolingual method.

This set the tone; teachers expected linguistics to say something to the language teacher. When Chomsky attacked Behaviourism, discrediting and in effect destroying it, language teachers expected him to provide alternative answers; they wanted Chomsky's TGG to guide their teaching. It was therefore inevitable that there would be attempts to incorporate the new ideas provided by generative linguistics and $\mathrm{L} 1$ researchers into second language teaching. Two methods, the cognitive code method and the cognitive anti-method, emerged, both drawing on different aspects of Chomsky's cognitivism.

Chomsky's view of language as a system of rules was interpreted in the cognitive code method to mean that perception and awareness of rules precedes the use of these rules, and that a conscious grammatical understanding of a language rule should precede the provision of opportunities for practice in language teaching (e.g. Chastain, 1971). Chomsky's insistence on the creative characteristics of the language faculty led to the rejection of mechanical practice and an emphasis on the creative an innovative use of language.

Proponents of the cognitive anti-method (such as Newmark, 1966; Newmark and Reibel, 1968) adopted a more radical method in which it was left to the learner to depend on his innate capacity and to control the learning process himself. Language acquisition was not seen as an additive process - a learner was supposed to learn 'whole chunks' at a time. It was not regarded as necessary to attend to linguistic form. This method was a radical alternative to the audiolingual method; it resembles ideas proposed by Krashen a decade later.

It is interesting to note that both these methods were based on one linguistic theory, but arrived at different and diverse interpretations.

The changes in linguistic theory in the 1970s saw a shift away from the study of language seen purely as a formal system towards the study of language as communication; a shift towards sociolinguistics, discourse analysis, semantics, 
speech act theory and pragmatics. This had a,major impact on language teaching, culminating in the so-called communicative approach to second language teaching, which was a reaction against the predominant formalistic view of language teaching. Its initial impact was on syllabus design. Wilkins (1976), influenced by Halliday's functional approach to language and Austin's speech acts, produced a notional syllabus which took the language teaching world by storm.

The work of the Council of Europe is another example of the change in approach in the 1970s. It was based on current semantic and sociolinguistic concepts, including Wilkins' notions and functions. The council developed their own syllabuses and produced inventories which specified situations in terms of learners' roles, settings and topics, and listed language activities, functions and notions (Van Ek, 1975).

Krashen's (e.g. 1982) influential theory of second language acquisition illustrates the increasing influence of psycholinguistics. It was only weakly based on Chomsky's theory, but it drew on second language acquisition research and Krashen confidently advocated the fundamental pedagogical principle of second language acquisition, namely the provision of comprehensible input, as the solution to second language teaching problems.

\section{Linguistics and second language teaching: an evaluation}

These examples illustrate a number of aspects related to the influence linguistics has had on second language teaching:

\section{A 'banners and bandwagon' effect}

There is clear evidence that linguistics has had a 'banners and bandwagon' effect on language teaching. We see some hasty applications, and equally hasty rejections of linguistic theory.

An inappropriate psychological theory in the form of Skinner's operant conditioning was taken over into linguistics and then applied to language teaching. There is little doubt that this application led to disappointing results in language teaching. The rejection of audiolingualism was therefore hasty and fierce. 
As a result of Chomsky's rejection of Behaviourism, there is now a widespread supposition that there is nothing whatever of any theoretical validity or pedagogical value in behaviourist thinking. Widdowson (1990, p.11), however, points out that total rejection of Behaviourism is no more reasonable than total acceptance. It is clear that there must be some aspects of language learning which have to do with habit formation. Widdowson (1990, p.11) states: "Effective communication depends on the immediate and automatic access to linguistic forms so that the mind can consciously engage in the more creative business of negotiating meaning. If these forms were not internalized as habitual mental patterns independent of thought, they could not be readily accessed and language could not function effectively as a means of thinking and communicating".

Some attempts to apply transformational grammar to second language teaching were also misguided. Chomsky's intention was to describe native-speaker competence rather than the process by which a learner may achieve competence in a second language. The rules to which he referred were not pedagogical explanations of language functioning but rules of great abstractness and intricacy, inherent in the structure of language, which there is no reason to suppose can be brought to conscious awareness. Chomsky's view did not provide justification for reintroducing into the classroom the explanation of traditional grammar rules.

Another example of an incomplete application of linguistics is to be found in the functional-notional syllabus. Austin's work is self-avowedly fragmentary and is insightful rather than comprehensively descriptive of language. Stern (1983, p.178) points out that Wilkins in fact moved ahead of linguistic theory at the time, as there was no available semantic or notional framework which he could use: the "practical demands of a communicative approach to language teaching ran ahead of existing theory and research". The Council of Europe's work was intended for adult language learning in continuing education, beyond formal schooling. Cultural co-operation in Europe was the ultimate aim of their proposals. Their proposed solution was transferred to schools, first in Europe, and later all over the world. Widdowson $(1990$, p.12) points out that "notionalfunctional syllabuses were peddled as nostrums all over the place as suitable for every situation". This was clearly not the case. The functional-notional syllabus 
has been severely criticised as just another manifestation of a static approach to language teaching (e.g. Widdowson, 1979).

Krashen's Monitor Theory has been accepted without reservation in refresher courses, and has been advocated as the final solution to all our language teaching problems. But it too, has come in for severe criticism (e.g. Gregg, 1984; Widdowson, 1990). For example, the absolute distinction between acquisition and learning is not supported empirically. Krashen's proposals are also not based on sound conclusions about second language acquisition research (they are based on morpheme studies which established an accuracy order for morpheme acquisition). As far as Krashen's linguistics is concerned, Gregg (1984, p.95) says that Krashen has no theory at all. Krashen's suggestions seem to be more pragmatic than anything else - the 'Natural Approach' seems to work. Lennon (1989, p.50) points out that any theoretical underpinnings of this method appear to be something of a post-hoc affair.

\section{Linguistic theory must be viewed critically}

It is clear that the teacher must be sceptic and critical of linguistic theory. All suggestions from the fundamental disciplines must be viewed with caution and scepticism. But, as Widdowson (1990, p.10) points out, this is different from disregarding them altogether.

One is reminded here of Chomsky's (1966, p.43) much-quoted scepticism about the significance of linguistics for language teaching. But what Chomsky in fact says is that linguistics and psychology are associated with ways of approaching 'the problems of language teaching from a principled point of view', in other words, the theoretical disciplines provide a reference for establishing principles of approach. He only questions whether these disciplines can inform pedagogic technique directly.

\section{Phases of influence}

These examples also illustrate the phases through which the influence of linguistics has gone. As I have mentioned, there is a continuum of influence of linguistics on language teaching: from a direct influence on language teaching methods and materials as in the case of the audiolingual method, to an indirect one on the approach to language teaching in the communicative era. Recently 
the relationship has therefore become mpre indirect and remote: from a confident 'application' of linguistics to a more indirect connection.

We thus see a shift from applying linguistics directly to treating linguistics as a resource to be drawn on for the benefit of pedagogy with complete independence of mind (Stern, 1983, p.174). This is a justified approach for the simple reason that linguistics and language teaching have different aims.

Wilkins (1972, p.216) cites three aims of linguistics: to study the human language faculty, to develop theories to explain language behaviour, and to provide the most efficient means for describing languages and to make the most accurate and comprehensive descriptions available. Linguistics is therefore concerned with the description of language structure as well as the description of language use (sociolinguistics) and language learning (psycholinguistics). It is not aimed at solving problems of language teaching.

The teacher's concern is with practical issues. Language teaching is in essence a problem-solving activity: the teacher must solve the problem of what to teach and how to teach the second language. He cannot proceed in an ad hoc manner, however. Every technique he uses can in fact be related to an underlying principle (cf. Widdowson, 1979). Language teaching can therefore be defined as a principled problem-solving activity.

This implies that the language teacher is not interested in the application of linguistics or any other discipline; he is interested in solving language teaching problems. And he will look at any subject which can assist him in doing so. It also implies that he will do so in a principled manner, so that his teaching can be related to underlying principles. This is where the applied linguist comes in.

\section{The role of applied linguistics}

Applied linguistics provides the bridge between the theoretical disciplines and language teaching. It is also a problem-solving enterprise; its raison d'être is solving practical problems. It therefore performs an essential function in the language teaching process. For example, linguistics provides language descriptions of a particular language. The need for this is sometimes obscured, but becomes obvious as soon as we approach less commonly taught languages. Two problems manifest themselves, however: on the one hand, language 
descriptions are often too technical and too theoretical for the language teacher; on the other hand, the demands of syllabuses based on semantic and pragmatic criteria have outstripped the available descriptive resources. Stern (1983, p.186) points out that it is necessary to have an intermediate device, a pedagogical grammar, which is an interpretation and selection for language teaching purposes of the description of a language, based not only on linguistic but also on educational and psychological criteria and used as a linguistic resource. This is where the applied linguist performs a valuable function.

\section{The teacher's approach to language teaching}

The linguistic sciences will always be behind the teacher. They have a direct influence on his approach to language teaching. Every teacher has an approach (conscious or unconscious) to language teaching. The task of language teaching prompts the teacher almost invariably to think about the nature of language; for example, his theory of language will determine whether he presents the language analytically or non-analytically to the learners. The rationale for his decision will imply a view of the nature of language or a theory of language. His method such as a decision about drill work - will likewise be based on a view of second language acquisition. A theory of second language teaching is therefore an important aspect of teaching and learning. It is generally agreed that what happens in the classroom will actually determine the success of the teaching; the major determinant of what happens is the second language acquisition theory.

An approach entails an answer to two questions: What is language? and How is a (second) language acquired?

For principled answers to these questions, teacher has to turn to the linguistic sciences; he must have some knowledge of linguistics. Linguistics therefore provides the teacher with an approach; with insights (e.g. the form/meaning distinction) and implications (e.g. for methods and techniques) for language teaching.

\section{Linguistics and second language acquisition}

Linguistics nowadays is not concerned with the organisation of language data so much as the nature of the organising power that is capable of handling such data. Linguistics can therefore provide an account of how a language is acquired. It 
seems as if many answers to the problems of.second language teaching are likely to come from this source. At present applied linguists are engaged in the search for a theory of second language acquisition (Gregg, 1984, p.95). I would briefly like to illustrate how this search is continuing and try to establish what contribution can be expected to come from linguistics.

\section{Universal Grammar}

Any theory of second language acquisition must include some sort of linguistic theory if it is to have any value as a theory. Universal Grammar (UG) is increasingly being used to explain how second languages are learnt. This endeavour links L2 learning to current ideas about language and language learning.

Chomsky's Universal Grammar is an innate linguistic structure which consists of linguistic principles applicable to all grammars. A number of options, called parameters, are built into the grammar, setting limits within which human languages can vary.

The theory is a theory of L1 acquisition; the question, of course, is whether it can shed any light on the problem of second language acquisition. The question to be answered is: does UG function in second language acquisition?

Empirical research is beginning to provide an answer to this question. A number of studies suggest that UG principles are available to the second language learner and that parameter resetting is possible (cf. White, 1989). Some learners clearly do attain complex and subtle knowledge which does not derive solely from the $\mathrm{L} 1$; this is unexplained if $\mathrm{L} 2$ learning proceeds only by means of general cognitive strategies such as hypothesis-testing and problem-solving. There are clear suggestions that UG must be involved in second language acquisition.

It is important in this regard to remember that the principles of UG, such as Subjacency, the ECP, the Theta Criterion, and Structure-dependency, are highly abstract. These are not the properties of language which language teachers teach. It is in fact not necessary to teach them. Learners do not need to learn them; they are built-in to the mind. Learners need to learn the parameter settings, however. Research indicates that first language settings of parameters are carried over to the second language (Cook, 1991, p.118). In order to set the 
values for the parameters, the learner only needs to be exposed to examples of the language. Thus an area where UG research offers potential implications for language teaching is over the question of what kind of evidence can be used to reset parameters (White, 1989, p.182). It is possible that specific grammar teaching and correction in the language classroom can sometimes fill a gap not covered by positive evidence from the L2. Cook (1991, p.118) states that L2 learners need to spend comparatively little effort on grammatical structure, since it results from the setting of a handful of parameters. They do however need to acquire an immense amount of detail about how individual words are used. The comparative simplicity of syntax learning in the UG model is achieved by increasing the burden of vocabulary learning. Cook (1991, p.119) points out that the future may indeed see the reorganization of the role of vocabulary teaching in second language teaching.

The UG model - which is confined to core aspects of syntax - is likely to prove an inadequate model on which to base the whole L2 teaching enterprise. Cook (1991, p.120) says: "Any view of the whole L2 learning system has to take on board more than the UG model. Classroom L2 teaching must include many aspects of language that are not covered by the model". It also seems unlikely that $\mathrm{L} 2$ acquisition would be confined to the Language Module and that other cognitive areas will not play any role in the acquisition process.

UG goes some way towards explaining how aspects of L2 knowledge are acquired in the first place. But this is not what teachers are solely concerned with. Ellis (1990, p.175) says: "Teachers are concerned with both how knowledge is acquired and crucially, with the learners' ability to make use of this knowledge". In this regard, Taylor (1988, p.166) makes a worthwhile distinction between competence and performance. He suggests that the term 'competence' be used for 'knowledge', while 'performance' be used for 'ability to use knowledge'.

This means that language teachers also need a theory of performance on which to base their teaching. They want to know how learners develop the ability to use their L2. As Chomsky is interested in competence only, it is clear that linguistics cannot provide answers to this question.

\section{Cognitive theory}


Applied linguists are therefore turning to cognitive theory in an attempt to find a theory of performance. One influential model is Anderson's (1983) 'cognitive behaviourist' model which sees learning as building up response strengths through a twofold division into procedural memory (procedures for doing things) and declarative memory (knowledge). Another model distinguishes between controlled and automatic processing (Posner and Snyder, 1975). Controlled processing is used initially in the learning of a new complex cognitive skill; it requires attention and extensive practice; it takes time; and can take place with or without any conscious awareness on the part of the learner. Automatization then follows; this is necessary because the learner has limited processing capacity and need to free capacity to deal with new information. The acquisition of new information leads to a restructuring of the learner's knowledge system: as learning takes place, the existing system is modified in order to take account of the new information.

A number of researchers have applied cognitive learning theory to second language acquisition. One such attempt is Bialystok's (1988). She argues that language is processed by the human mind in the same way as other kinds of information. Her model distinguishes between an analysed and an automatic factor. The analysed factor concerns the extent to which the learner is aware of the structure of his linguistic knowledge. The automatic factor concerns the relative access which the learner has to knowledge. Knowledge gains in automaticity as learning takes place, and automaticity is achieved through practice.

The main application of this theory to teaching is the emphasis on practice as the key to second language learning. Practice builds up the weightings, response strengths and so on that determine how language is processed and stored (Cook 1991, p.123). The classroom should therefore maximize practice by learners. This model reminds us that language is also behaviour and skill. As Cook (1991, p.123) puts it: "As well as the aspects of language that are abstract or under conscious control, there are skills learnt by doing them over and over again".

Cognitive theory does not provide a complete account of language development. It is a partial account only. For example, it cannot account for the fact that there are acquisitional sequences which are immune to instruction (Ellis 1990, p.182). Instruction cannot change the order in which certain developmental structures are acquired. Thus the basic assumption of cognitive theory, namely that 
language learning is not different in kind from other kinds of skill learning, is not fully justified.

It is clear that second language acquisition (SLA) is a complex issue. There is no single comprehensive account of SLA, but only a number of incomplete and partial accounts. It would indeed be difficult for one theory to account for the entire range of second-language phenomena, especially if one considers also personality factors and environmental factors. The trend has been to move away form a general theory of SLA to theories of more limited scope. This makes the task of the applied linguist an extremely difficult one. He often has to cope with contradictory implications. UG and cognitive theory, for example, differ on the issue of practice. The UG model sets minimal store by practice: in principle a parameter can be set by a single example for ever more. Cognitive models see language as the gradual accumulation of preferred ways of doing things, making practice an essential requirement (Cook, 1991, p.123).

\section{Conclusion}

Language is the very concept with which the language teacher's whole career is concerned. There is little doubt that the linguistic sciences have an essential role to perform. Their place is behind the classroom teacher: in determining his approach to language teaching. Linguistics provides important implications for the preparation of syllabuses, teaching programmes, materials and methodology. The language teacher cannot proceed without the linguistic sciences, but as I have indicated, he must retain a critical stance at all times. Not all the answers are likely to come from linguistic theory, however. Its contribution in terms of second language acquisition, although useful, seems somewhat limited. Applied linguistics is therefore in the process of extending its horizons, turning to unfamiliar territory, such as cognitive psychology, for answers to problems which teachers have to face.

\section{BIBLIOGRAPHY}

ANDERSEN,J. 1983. The architecture of cognition. Cambridge, Mass.: Harvard University Press. 
BIALYSTOK, ELLEN. 1988. Psycholinguistic dimensions of second language proficiency. In Rutherford, W. and Sharwood-Smith, M. (eds). Grammar and second language teaching. Rowley, Mass.: Newbury House.

CHASTAIN, K. 1971. Developing second-language skills: theory to practice. Chicago: Rand McNally.

CHOMSKY, N. 1966. Linguistic theory. In Mead, R.G. Jr (ed). Language teaching: broader contexts. Northeast conference on the teaching of foreign languages: reports of the working committee. New York: MLA Materials Center.

COOK, V. 1991. Second language leaming and language teaching. London: Edward Arnold.

ELLIS, R. 1990. Instructed second language acquisition. Oxford: Basil Blackwell.

GREGG, K. 1984. Krashen's monitor and Occam's razor. Applied Linguistics $5(2): 79-100$.

HALLIDAY, M.A.K., McINTOSH, A. and STREVENS, P. 1964. The linguistic sciences and language teaching. London: Longman.

KRASHEN, S. 1982. Principles and practice in second language acquisition: Oxford: Pergamon.

JOHNSON, K. 1982. Communicative syllabus design and methodology. Oxford: Pergamon.

LENNON, P. 1989. The linguist and the language teacher: love at first sight or the end of the honeymoon? In A Forum anthology: selected articles from the English Teaching Forum 1984-1988. Washington, D.C.: United States Information Agency.

NEWMARK, L. 1966. How not to interfere in language learning. International Joumal of American Linguistics 32:77-83. 
NEWMARK, L. and REIBEL, D. 1968. Necessity and sufficiency in language learning. International Review of Applied Linguistics in Language Teaching 6:145164.

POSNER, M and SNYDER, C. 1975. Attention and cognitive control. In Solso, $\mathrm{R}$. (ed). Information processing and cognition: the Loyola symposium. Hillsdale, NJ: Lawrence Erlbaum.

SAMPSON, G. 1980. Schools of linguistics. London: Hutchinson.

STERN, H.H. 1983. Fundamental concepts of language teaching. Oxford: Oxford University Press.

TAYLOR, D. 1988. The meaning and use of the term 'competence' in linguistics and applied linguistics. Applied Linguistics 9(2):148-168.

VAN EK, J. A. 1975. The threshold level in an European unit/credit system for modern language learning by adults. Strasbourg: Council of Europe.

WIDDOWSON, H.G. 1979. Explorations in applied linguistics. Oxford: Oxford University Press.

WIDDOWSON, H.G. 1990. Aspects of language teaching. Oxford: Oxford University Press.

WILKINS, D.A. 1972. Linguistics in language teaching. London: Edward Arnold.

WILKINS, D.A. 1976. Notional syllabuses. London: Oxford University Press.

WHITE, LYDIA. 1989. Universal Grammar and second language acquisition. Amsterdam: John Benjamins. 